\title{
ANALISIS BREAK EVEN POINT (BEP)
}

\author{
Priskila Manuho ${ }^{1}$, Zevania Makalare ${ }^{2}$, Trixie Mamangkey ${ }^{3}$, Novi Swandari Budiarso ${ }^{4}$ \\ 1,2,3 Jurusan Akuntansi, Fakultas Ekonomi dan Bisnis, Universitas Sam Ratulangi, Jl. Kampus Bahu, Manado, \\ 95115, Indonesia \\ ${ }^{4}$ Program Studi Profesi Akuntan, Fakultas Ekonomi dan Bisnis, Universitas Sam Ratulangi, Jl. Kampus Bahu, \\ Manado, 95115, Indonesia \\ E-mail: priskilamanuho16@gmail.com ${ }^{1}$
}

\begin{abstract}
This paper aims to provide information to the public regarding the meaning, use, purpose, limitations, and methods of calculating Break Even Point Analysis (BEP). Management needs information that can be used as a basis for planning company profits. By knowing the breakeven point, management can determine the amount of production or sales that must be made, according to the profit target to be achieved). Due to the Covid-19 pandemic, the data collection technique used is an online study, namely by taking references from the Internet. The type of data used is secondary data in the form of books related to the discussion, of course, books/materials on the internet. Data analysis used descriptive method, which was to describe the research results and then draw conclusions. Break Even Point (BEP) calculation can be done by equation method, contribution margin method, and graphical method. The three methods when used produce the same number. Break Even Point (BEP) analysis, in practice, besides containing benefits but also contains weaknesses.
\end{abstract}

Keywords: break even points; break-even point; profit planning

\section{PENDAHULUAN}

Break Even Point (BEP) merupakan kondisi yang bisa terjadi pada perusahaan, yaitu suatu kondisi perusahaan dalam operasionalnya tidak mendapat keuntungan dan juga tidak menderita kerugian. Dengan kata lain, antara pendapatan dan biaya ada pada kondisi yang sama, sehingga laba perusahaan adalah nol (penghasilan=total biaya). Analisa BEP adalah suatu teknik analisa untuk mempelajari hubungan antara volume penjualan dan profitabilitas. Laba bersih akan diperoleh bila volume penjualan melebihi biaya yang dikeluarkan, sedangkan perusahaan akan menderita kerugian bila penjualan hanya cukup untuk menutup sebagian biaya yang dikeluarkan, dapat dikatakan di bawah titik impas. Analisis BEP juga sangat membantu manajemen dalam perencanaan dan pengambilan keputusan. Tujuan analisis titik impas adalah untuk mengetahui tingkat aktivitas dimana pendapatan hasil penjualan sama dengan jumlah semua biaya variabel dan biaya tetapnya. Apabila suatu perusahaan hanya mempunyai biaya variabel saja, maka tidak akan muncul masalah titik impas dalam perusahaan tersebut. Masalah titik impas akan muncul apabila suatu perusahaan memiliki biaya variabel dan biaya tetap. Besarnya biaya variabel secara keseluruhan akan berubah-ubah sesuai dengan perubahan volume produksi, sedangkan besarnya biaya tetap secara keseluruhan tidak mengalami perubahan meskipun ada perubahan volume produksi. Adapun biaya yang termasuk golongan biaya variabel pada umumnya adalah bahan mentah, upah buruh langsung (direct labor), dan komisi penjualan sedangkan yang termasuk golongan biaya tetap pada umumnya adalah depresiasi aktiva tetap, sewa, bunga utang, gaji pegawai, gaji pimpinan, gaji staf riset, dan biaya kantor.

Analisis BEP berguna apabila beberapa asumsi dasar dipenuhi. Dalam kenyataan yang sebenarnya lebih banyak asumsi yang tidak dapat dipenuhi. Namun demikian perubahan asumsi ini tidak mengurangi validitas dan kegunaan analisa BEP sebagai suatu alat bantu 
pengambilan keputusan hanya saja diperlukan suatu modifikasi tertentu dalam penggunaannya. Secara umum manfaat analisis BEP adalah untuk mengetahui titik pulang pokok dari sebuah usaha. Informasi titik pulang pokok menyebabkan manajemen dapat mengetahui harus memproduksi atau menjual pada jumlah berapa unit agar peruasahaan tidak mengalami kerugian. Kelemahan dari analisa BEP antara lain hanya ada satu macam barang yang diproduksi atau dijual. Jika lebih dari satu macam maka kombinasi atau komposisi penjualannya (sales mix) akan tetap konstan. Jika dilihat kondisi saat ini, kebanyakan perusahaan menciptakan banyak produk untuk meningkatkan daya saingnya mereka sehingga penerapan analisa BEP menjadi sulit. Asumsi lainnya adalah harga jual per satuan barang, jumlah satuan barang yang dijual, atau harga secara umum tidak mengalami perubahan.

Analisa BEP memiliki jangka waktu penerapan terbatas, biasanya hanya digunakan di dalam pembuatan proyeksi operasi selama setahun. Apabila perusahaan mengeluarkan biayabiaya untuk advertensi ataupun biaya lainnya yang cukup besar dimana hasil dari pengeluaran tersebut (tambahan investasi) tidak akan terlihat dalam waktu yang dekat sedangkan operating cost sudah meningkat, maka sebagai akibatnya jumlah pendapatan yang harus dicapai menurut analisa BEP agar dapat menutup semua biaya-biaya operasi yang bertambah besar juga. Menghitung BEP dapat menggunakan metode persamaan, metode kontribusi unit, maupun metode grafis.

\section{TINJAUAN PUSTAKA}

BEP adalah titik pulang pokok dimana jumlah pendapatan adalah sama dengan total biaya (Anderson et al., 2019:15). Terjadinya titik pulang pokok tergantung pada lama arus penerimaan sebuah proyek dapat menutupi segala biaya operasi dan pemeliharaan beserta biaya modal lainnya. Analisis BEP adalah teknik analisis untuk mempelajari hubungan antara biaya, laba, dan volume penjualan atau Cost, Profit, and Volume analysis (CPV analysis) khususnya dalam merencakan laba (Blocher et al., 2010:328). Hal ini mengimplikasikan bahwa perusahaan dengan volume penjualan di bawah titik BEP akan menderita kerugian karena keuntungan yang diterima masih menutupi biaya yang dikeluarkan.

Perusahaan perlu merencanakan berapa besar laba yang ingin diperoleh dalam rangka memproduksi atau menghasilkan suatu produk, baik barang maupun jasa dimana salah satu cara adalah menentukan nilai BEP (Block et al., 2017:130). Bukti empiris dari Sugiarti (2005), Irfania dan Diyani (2016), Makmur (2016), Mokoginta dan Budiarso (2017), Chalil (2018), Maruta (2018), Suswadi (2018), Julirin et al. (2019), Khanifah dan Septiana (2019), dan Nata et al. (2021) menunjukkan bahwa BEP memiliki peranan penting bagi perusahaan dalam merencanakan laba jangka pendek. Garrison et al. (2018:199), dan Mowen et al. (2018:334) menyatakan bahwa untuk mencari BEP dapat digunakan rumus sebagai berikut:

BEP (unit)

$=\frac{\text { Biaya Tetap }}{\text { Harga jual per unit }- \text { Biaya variabel per unit }}$

BEP (unit)

BEP (mata uang)

$$
=\frac{\text { Biaya Tetap }}{1-(\text { Biaya variabel per unit/Harga jual per unit })}
$$

\section{METODE DAN TEKNIK PENERAPAN IPTEKS}

3.1. Metode penerapan ipteks

Penerapan ipteks ditempuh dengan menggunakan metode deskriptif melalui pendekatan contoh kasus perhitungan analisa BEP. 


\subsection{Teknik penerapan ipteks}

Teknik yang digunakan untuk penerapan ipteks adalah dengan memberikan contoh perhitungan sesuai dengan metode perhitungan BEP yaitu dengan menggunakan pendekatan matematis yang terbagi dalam dua bentuk perhitungan yaitu dalam unit dan dalam mata uang.

\section{PEMBAHASAN}

\subsection{Asumsi kasus 1}

PT. X menghasilkan sebuah produk dengan harga jual produk per unit (HJ) sebesar IDR 100. Produk tersebut memiliki biaya produksi yang terdiri dari biaya tetap (BT) sebesar IDR 250.000 dan biaya variabel (BV) per unit sebesar IDR 50. Persamaan matematis atas biaya produksi PT. $\mathrm{X}$ dinyatakan berikut.

$$
\begin{gathered}
\mathrm{Y}=\alpha+\beta . \mathrm{X} \\
\mathrm{TC}=250.000+50 . \mathrm{X}
\end{gathered}
$$

TC adalah total biaya (total cost) dan $\mathrm{X}$ adalah unit produk yang diproduksi. Berdasarkan informasi harga jual per unit dan biaya-biaya dari produk maka penghitungan titik BEP dalam jumlah unit dapat dilakukan berikut.

$$
\begin{aligned}
\mathrm{BEP} \text { (unit) } & =\frac{\mathrm{BT}}{\mathrm{HJ}-\mathrm{BV}} \\
& =\frac{250.000}{100-50} \\
& =\frac{250.000}{50} \\
& =5.000 \text { unit }
\end{aligned}
$$

Hasil perhitungan menunjukkan bahwa titik BEP dalam jumlah unit untuk PT. X adalah sebanyak 5.000 unit. Hasil ini mengimplikasikan bahwa untuk mencapai laba sama dengan nol maka PT. X harus menjual 5.000 unit. Selain itu, PT. X juga dapat menentukan titik BEP yang dinyatakan dalam mata uang dengan penghitungan berikut.

$$
\begin{aligned}
\mathrm{BEP}(\text { mata uang }) & =\frac{\mathrm{BT}}{1-(\mathrm{BV} / \mathrm{HJ})} \\
& =\frac{250.000}{1-(50 / 100)} \\
& =\frac{250.000}{0.50} \\
& =\text { IDR } 500.000
\end{aligned}
$$

Hasil perhitungan menunjukkan bahwa titik BEP dalam mata uang untuk PT. X adalah sebesar IDR 500.000. Hasil ini mengimplikasikan bahwa untuk mencapai laba sama dengan nol maka PT. X harus mencapai tingkat penjualan sebesar IDR 500.000. Laporan laba rugi atas pembuktian titik BEP dari PT. X dapat disajikan berikut. 
Penjualan

Biaya variabel

Laba kontribusi

Biaya tetap

\section{Laba bersih}

5.000 unit $x$ IDR 100

5.000 unit $x$ IDR 50
IDR 500.000

250.000

250.000

250.000

Tabel 1 menyajikan informasi penghitungan BEP dari PT. X yang dapat digunakan untuk membentuk grafik BEP.

Tabel 1. Titik BEP PT. $X$

\begin{tabular}{rccccrcr}
\hline \multicolumn{1}{c}{ Unit } & HJ & BV & B & TP & TBV & TB & \multicolumn{1}{c}{ L/R } \\
\hline 1,000 & 100 & 50 & 250,000 & 100,000 & 50,000 & 300,000 & $(200,000)$ \\
2,000 & 100 & 50 & 250,000 & 200,000 & 100,000 & 350,000 & $(150,000)$ \\
3,000 & 100 & 50 & 250,000 & 300,000 & 150,000 & 400,000 & $(100,000)$ \\
4,000 & 100 & 50 & 250,000 & 400,000 & 200,000 & 450,000 & $(50,000)$ \\
5,000 & 100 & 50 & 250,000 & 500,000 & 250,000 & 500,000 & - \\
6,000 & 100 & 50 & 250,000 & 600,000 & 300,000 & 550,000 & 50,000 \\
7,000 & 100 & 50 & 250,000 & 700,000 & 350,000 & 600,000 & 100,000 \\
8,000 & 100 & 50 & 250,000 & 800,000 & 400,000 & 650,000 & 150,000 \\
9,000 & 100 & 50 & 250,000 & 900,000 & 450,000 & 700,000 & 200,000 \\
10,000 & 100 & 50 & 250,000 & $1,000,000$ & 500,000 & 750,000 & 250,000 \\
\hline
\end{tabular}

Gambar 1 menggambarkan titik BEP berdasarkan informasi penghitungan yang disajikan dalam Tabel 1.

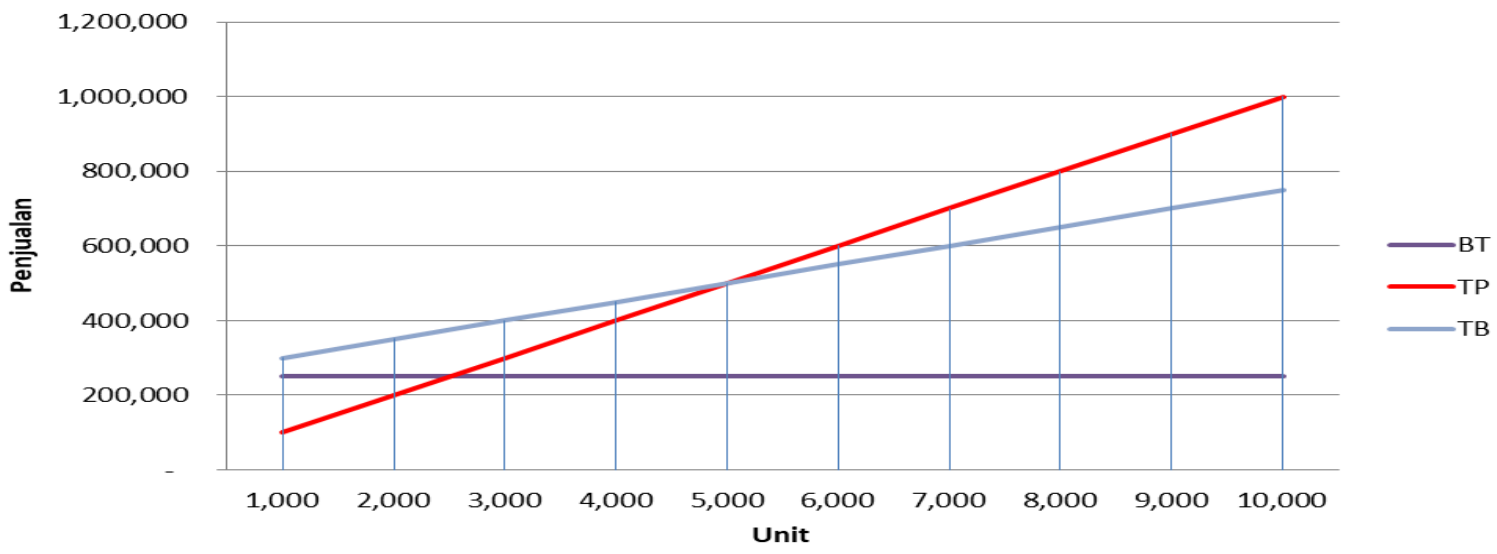

Gambar 1. Titik BEP

\subsection{Asumsi kasus 2}

PT. X menjual produknya dengan harga jual (HJ) IDR 100 per unit dan untuk itu perusahaan harus mengeluarkan biaya variabel (BV) sebesar IDR 60 per unit dan biaya tetap (BT) sebesar IDR 25.000. Pihak manajemen merencanakan untuk mencapai target laba sebelum bunga dan pajak (TL) sebesar IDR 10.000. Penghitungan titik penjualan dari PT. X dapat dihitung sebagai berikut. 


$$
\begin{aligned}
\mathrm{BEP}(\text { unit }) & =\frac{\mathrm{BT}+\mathrm{TL}}{\mathrm{HJ}-\mathrm{BV}} \\
& =\frac{25.000+10.000}{100-60} \\
& =\frac{35.000}{40} \\
& =875 \text { unit }
\end{aligned}
$$

Hasil perhitungan menunjukkan bahwa titik penjualan dalam jumlah unit untuk PT. X adalah sebanyak 875 unit. Hasil ini mengimplikasikan bahwa untuk mencapai laba sama dengan IDR 10.000 maka PT. $X$ harus menjual 875 unit walaupun titik BEP yang seharusnya dari PT. X adalah sebesar 625 unit. Selain itu, PT. X juga dapat menentukan titik penjualan yang dinyatakan dalam mata uang dengan penghitungan berikut.

$$
\begin{aligned}
\mathrm{BEP}(\text { mata uang }) & =\frac{\mathrm{BT}+\mathrm{TL}}{1-(\mathrm{BV} / \mathrm{HJ})} \\
& =\frac{25.000+10.000}{1-(60 / 100)} \\
& =\frac{35.000}{0.40} \\
& =\quad \mathrm{IDR} 87.500
\end{aligned}
$$

Hasil perhitungan menunjukkan bahwa titik penjualan dalam mata uang untuk PT. X adalah sebesar IDR 87.500. Hasil ini mengimplikasikan bahwa untuk mencapai laba sama dengan IDR 10.000 maka PT. X harus mencapai tingkat penjualan sebesar IDR 87.500 walaupun titik

\begin{tabular}{|c|c|}
\hline 625 unit & 875 unit \\
\hline IDR 62.500 & IDR 87.500 \\
\hline 37.500 & 52.500 \\
\hline 25.000 & 35.000 \\
\hline 25.000 & 25.000 \\
\hline $\mathbf{0}$ & 10.000 \\
\hline
\end{tabular}
BEP yang seharusnya dari PT. X adalah sebesar IDR 62.500. Laporan laba rugi atas pembuktian titik penjualan dan titik BEP dari PT. X dapat disajikan berikut.

Penjualan 625 unit 875 unit

Biaya variabel Laba kontribusi

Tabel 2 menyajikan informasi penghitungan BEP dengan tambahan target laba dari PT. X yang dapat digunakan untuk membentuk grafik BEP. 
Tabel 2. Titik BEP dengan target laba

\begin{tabular}{cccccccr}
\hline Unit & HJ & BV & B T & TP & TBV & TB & L/R \\
\hline 550 & 100 & 60 & 25,000 & 55,000 & 33,000 & 58,000 & $-3,000$ \\
575 & 100 & 60 & 25,000 & 57,500 & 34,500 & 59,500 & $-2,000$ \\
600 & 100 & 60 & 25,000 & 60,000 & 36,000 & 61,000 & $-1,000$ \\
625 & 100 & 60 & 25,000 & 62,500 & 37,500 & 62,500 & 0 \\
650 & 100 & 60 & 25,000 & 65,000 & 39,000 & 64,000 & 1,000 \\
675 & 100 & 60 & 25,000 & 67,500 & 40,500 & 65,500 & 2,000 \\
700 & 100 & 60 & 25,000 & 70,000 & 42,000 & 67,000 & 3,000 \\
725 & 100 & 60 & 25,000 & 72,500 & 43,500 & 68,500 & 4,000 \\
750 & 100 & 60 & 25,000 & 75,000 & 45,000 & 70,000 & 5,000 \\
775 & 100 & 60 & 25,000 & 77,500 & 46,500 & 71,500 & 6,000 \\
800 & 100 & 60 & 25,000 & 80,000 & 48,000 & 73,000 & 7,000 \\
825 & 100 & 60 & 25,000 & 82,500 & 49,500 & 74,500 & 8,000 \\
850 & 100 & 60 & 25,000 & 85,000 & 51,000 & 76,000 & 9,000 \\
875 & 100 & 60 & 25,000 & 87,500 & 52,500 & 77,500 & 10,000 \\
900 & 100 & 60 & 25,000 & 90,000 & 54,000 & 79,000 & 11,000 \\
\hline
\end{tabular}

Gambar 2 menggambarkan titik BEP berdasarkan informasi penghitungan yang disajikan dalam Tabel 2.

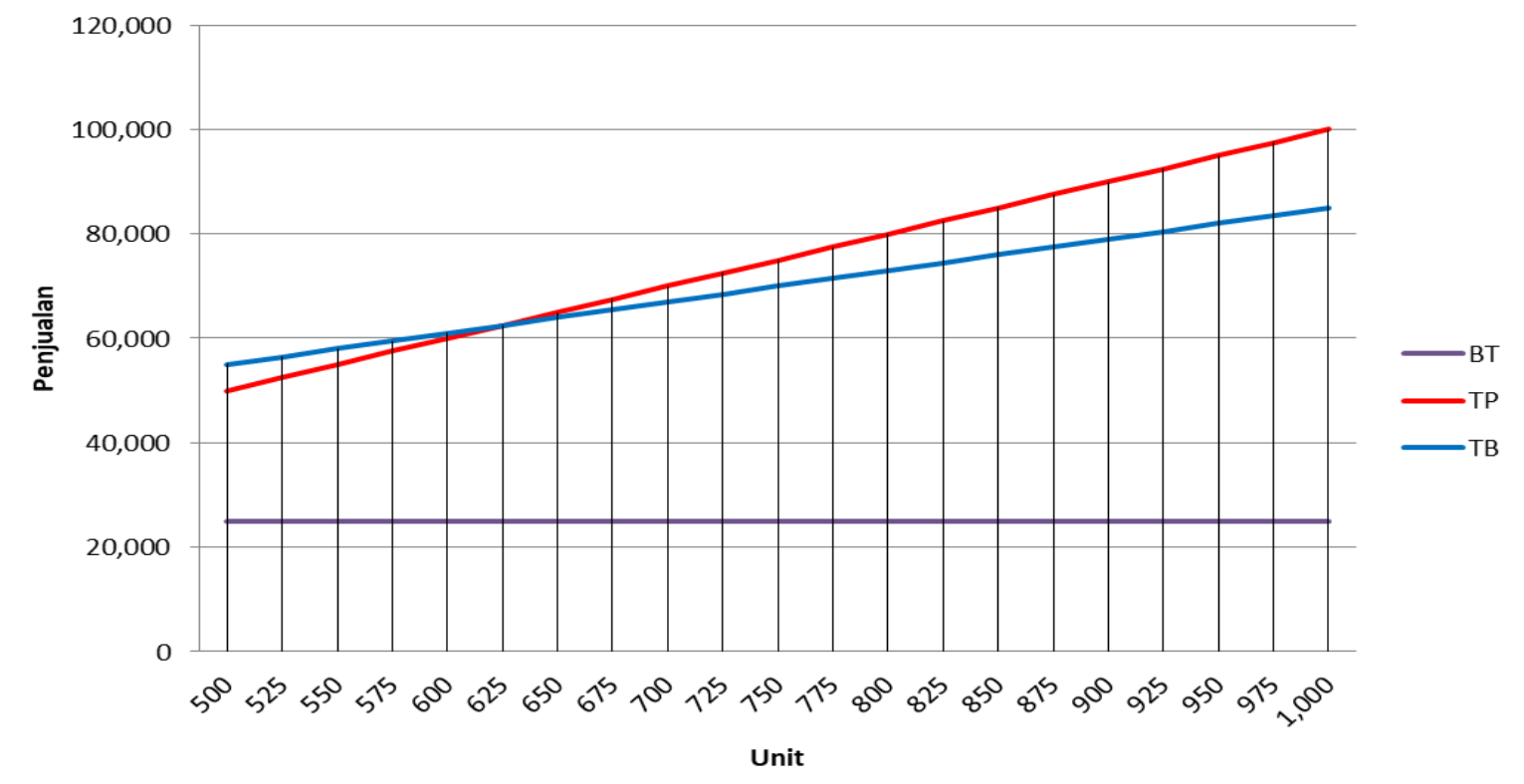

\section{Gambar 2. Titik BEP dengan target laba}

\section{KESIMPULAN DAN SARAN}

\subsection{Kesimpulan}

BEP dapat diartikan sebagai suatu titik atau keadaan dimana perusahaan didalam operasinya tidak memperoleh keuntungan dan tidak menderita kerugian. Tujuan dari analisis BEP yaitu untuk mengetahui pada volume penjualan atau produksi berapakah suatu perusahaan akan mencapai laba tertentu. Analisis BEP secara umum dapat memberikan informasi kepada pimpinan, bagaimana pola hubungan antara volume penjualan, biaya, dan tingkat keuntungan yang akan diperoleh pada level penjualan tertentu. Analisis BEP dapat dirasakan manfaatnya apabila titik BEP dapat dipertahankan selama periode tertentu. 
Keadaan ini dapat dipertahankan apabila biaya-biaya dan harga jual adalah konstan, karena naik turunnya harga jual dan biaya akan mempengaruhi titik BEP.

\subsection{Saran}

Apabila suatu perusahaan memproduksi lebih dari satu macam produk maka komposisi atau perbandingan antara satu produk dengan produk lain (sales mix) haruslah tetap. Karena keadaan ini dapat dipertahankan apabila biaya-biaya dan harga jual adalah konstan, karena naik turunnya harga jual dan biaya akan mempengaruhi titik BEP. Jadi, tujuan dari analisis BEP yaitu untuk mengetahui pada volume penjualan atau produksi berapakah suatu perusahaan akan mencapai laba tertentu.

\section{DAFTAR PUSTAKA}

Anderson, D. R., Sweeney, D. J., Williams, T. A., Camm, J. D., Cochran, J. J., Fry, M. J., \& Ohlmann, J. W. (2019). An introduction to management science: Quantitative approaches to decision making, $15^{\text {th }}$ Edition. Boston: Cengage Learning, Inc.

Blocher, E. J., Stout, D. E., \& Cokins, G. (2010). Cost management: A strategic emphasis, $5^{\text {th }}$ Edition. New York: McGraw-Hill/Irwin.

Block, S. B., Hirt, G. A., \& Danielsen, B. R. (2017). Foundations of financial management, $16^{\text {th }}$ Edition. New York: McGraw-Hill Education.

Chalil, D. C. (2018). Titik impas dan perencanaan laba. Jurnal Mitra Manajemen, 2(5), 438448. https://doi.org/10.52160/ejmm.v2i5.135

Garrison, R. H., Noreen, E. W., \& Brewer, P. C. (2018). Managerial accounting, 16th Edition. New York: McGraw-Hill Education.

Irfania, Y., \& Diyani, L. A. (2016). Perbandingan full costing, variable costing terhadap HPP serta perhitungan titik impas UKM Tempe Papan Mas. Jurnal Mahasiswa Bina Insani, $\quad 1(1), \quad 103-118 . \quad$ https://ejournalbinainsani.ac.id/index.php/JMBI/article/view/59

Julirin, M., Hasanuddin, \& Koto, H. (2019). Analysis of efficiency and break even point of sawmill wood industry: Case study at UD. Timber Jaya Makmur Sukaraja, Seluma, Bengkulu. Jurnal Agroindustri, $\quad 9(2), \quad 102-108$. https://doi.org/10.31186/j.agroindustri.9.2.102-108

Khanifah, K. E., \& Septiana, N. (2019). Profit planning analysis with Break Even Point approach (BEP) on banana chips business "Berkah Jaya" in Metro City. Fidusia: Jurnal Keuangan dan Perbankan, 2(2), 52-68. https://doi.org/10.24127/jf.v2i2.454

Makmur (2016). Analisis biaya produksi dan titik impas usaha kecil pembuatan sari jahe instan. Jurnal Cano Ekonomos, 5(1), 55-62. journal.upp.ac.id/index.php/Cano/article/view/1163

Maruta, H. (2018). Analisis Break Even Point (BEP) sebagai dasar perencanaan laba bagi manajemen. Jurnal Akuntansi Syariah, 2(1), 9-28. https://ejournal.stiesyariahbengkalis.ac.id/index.php/jas/article/view/129

Mokoginta, M., \& Budiarso, N. (2017). Ipteks bagi masyarakat perencanaan pajak jangka pendek. Jurnal Ipteks Akuntansi Bagi Masyarakat, 1(1), 1-13. https://doi.org/10.32400/jiam.1.1.2017.19639

Mowen, M. M., Hansen, D. R., \& Heitger, D. L. (2018). Managerial accounting: The cornerstone of business decision making, $7^{\text {th }}$ Edition. Boston: Cengage Learning.

Nata, A. A. L., Riani, N., Marantika, A., \& Apriani, E. (2021). Perencanaan laba dengan titik impas sebagai dasar pengambilan keputusan bagi pihak pengelola CV. Randu Sari Satu. Derivatif: Jurnal Manajemen, 15(1), 43-56. https://fe.ummetro.ac.id/ejournal/index.php/JM/article/view/579 
Sugiarti, S. (2005). Analisis titik impas dan keuntungan usaha tani karet di Desa Talang Perapat Kecamatan Seluma Barat Kabupaten Seluma. Jurnal AGRISEP, 4(2), 28-32. https://ejournal.unib.ac.id/index.php/agrisep/article/view/647

Suswadi, S. (2018). Analisis titik impas, tingkat efisiensi dan tingkat karakteristik pertanian organik di Boyolali. Jurnal Ilmiah Agrineca, 18(2), 43-58. http://ejournal.utp.ac.id/index.php/AFP/article/view/765 